\title{
The Presentation Form of Mamözi Göndra Music In Accompanying Nias War Dance on Furai Studio of Medan
}

\author{
Agustynus Saputra Simamora \\ Music Education Study Program
}

\begin{abstract}
The result of this study indicates that the presence of music mamözi göndra which is inherited by their ancestors is still extant. A way of presenting music mamözi göndra divided into three sections: preparation before the music mamözi göndra performed before the word fahugo used, after fahugo used musical instruments mamözi göndra played together in the show, the process of closing music mamözi göndra done only with the code of the trainer music or göndra mamözi music artists. There are five music functions mamözi göndra namely : The function of entertainment, self-expression, communication, a dance, economics. Göndra mamözi musical instruments used are göndra as a carrier tempo and pulse, faritia as the carrier beats / pulse, aramba as a guide to determine the initial knock.
\end{abstract}

Key word: Music Presentation form, Mamözi Göndra, The Nias war dance. 


\section{PENDAHULUAN}

Pada masyarakat Sumatera Utara kebudayaan yang hidup dan melekat di dalam lingkungan masyarakatnya sangat beraneka ragam karena terdiri dari beberapa suku, seperti suku Batak Toba, Karo, Simalungun, Angkola, Mandailling, Nias, Pak-pak, Melayu dan sebagian lagi penduduknya adalah masyarakat pendatang yang di dominasi oleh suku Jawa. Suku Nias terletak di Pulau Nias berdekatan dengan Pulau Sumatera yang berada di Provinsi Sumatera Utara, dan Nias merupakan salah satu suku yang berada terpisah dari Pulau Sumatera yang letaknya berada ditengah Laut Hindia Nias memiliki 4 Kabupaten dan 1 Kotamadya yaitu: Kabupaten Nias, Nias Selatan, Nias Barat, Nias Utara, dan Kotamadya Gunung Sitoli. Kebudayaan nias memiliki jenis Musik dan Tari yaitu, Musik Mamözi Göndra, Musik famolaya, Tari Perang (baluse), tari moyo, dan Tari lompat batu.

Seni tari yang terkenal yang berasal dari Nias adalah tari hombo batu (lompat batu), maena, moyo, dan lainlain. Begitu juga seni musiknya yang disebut dengan ensambel göndra dan penulisanya juga berbeda, Seperti yang terlihat didalam tulisan mamözi göndra ( huruf Ö yang bertitik dua diatasnya dibaca menjadi huruf $\mathrm{E}$ yang dibaca menjadi mamezi gendra ). Kegiatan musik Nias disebut dengan Mamözi göndra yaitu suatu ensambel dan seperangkat alat musik yang terdiri dari 1 buah göndra (gendang membranophone), 2 buah faritia (suspended idiophone gongs), dan 1-3 buah aramba (idiophon ,eknobbed, gongs).

Mamözi Göndra terdiri dari 2 kata dasar dalam bahasa Nias, yaitu Mamözi dan göndra. Mamözi artinya memukul dan göndra artinya alat musik nias yang bentuknya menyerupai sebuah alat musik yang terbuat dari kulit kambing, ataupun lembu yang telah diolah dan dikeringkan. Badan Göndra dibuat dengan kayu dari pohon besar yang dikerok dan telah dikeringkan terlebih dahulu. Di daerah lain, alat musik ini dinamakan sebagai beduk. Jika diterjemahkan ke dalam bahasa Indonesia, Mamözi Göndra adalah memukul beduk.

Mamözi Göndra mempunyai 2 arti, yaitu memukul beduk dan memukul seperangkat Göndra ( yang terdiri dari Göndra, Faritia, dan Aramba) dimana 
masing-masing mempunyai fungsi yang berbeda, fungsi dari Mamözi Göndra dulunya adalah sebagai pemberitahuan untuk menghimbau masyarakat untuk berkumpul, sebagai tanda pedoman waktu bagi masyarakat dalam suatu desa, sebagai simbol pengesahan bahwa telah dilakukannya pengangkatan gelar ataupun pembuatan hukum adat, dan sebagai tanda sekaligus pemberitahuan kepada masyarakat di dalam suatu desa bahwa sedang berlangsungnya acara adat, pemberitahuan ini dapat berupa owasa (acara memasuki rumah baru, ataupun pengangkatan gelar bangsawan), fondrakö (acara pengesahan hukum adat), falöwa (upacara perkawinan), dan zi mate (upacara kematian). Pada zaman sekarang sebagian fungsi dari Mamözi Göndra telah berubah. Contoh perubahan fungsi dari Mamözi Göndra yang terjadi adalah untuk memberitahukan ataupun mengundang masyarakat untuk berkumpul dan dalam upacara kematian. Pada kedua kasus tersebut, Mamözi Göndra tidak lagi dipergunakan, disebabkan karena terjadinya perubahan kebudayaan yang memanfaatkan teknologi, seperti surat undangan atau handphone untuk mengumpulkan masyarakat, dan juga terjadinya perubahan kebudayaan yang mengikuti tradisi Barat pada upacara kematian.

Fungsi dalam Tari perang untuk mempertahankan kekuasaan dan kampungnya dari serangan penduduk kampung lain, Tari Perang merupakan lambang kesatria para pemuda di desa desa di Nias, untuk melindungi desa dari ancaman musuh, yang diawali dengan Fana'a atau dalam Bahasa Indonesia disebut dengan ronda atau siskamling. Pada saat ronda itu jika ada aba-aba bahwa desa telah diserang oleh musuh maka seluruh prajurit berhimpun untuk menyerang musuh, hal ini sudah tidak dilakukan lagi karena sudah tidak ada lagi perang suku di Nias. Pada saat ini tari perang Nias hanya digunakan dalam penyambutan tamu istimewa dan pernikahan dalam suku Nias.

Tari perang yang dilaksanakan oleh suku Nias diiringi dengan Mamözi Göndra. Terdapat beberapa jenis alat musik tradisional dalam musik Mamözi Göndra, Alat-alat musik tersebut dimainkan oleh masyarakat Nias itu sendiri. Tari perang Nias yang diiringi dengan musik Mamözi Göndra dapat ditemukan disanggar Furai Medan. Sanggar Furai merupakan tempat untuk 
latihan suku Nias dalam Musik dan Tari, seperti halnya dengan Musik Mamözi Göndra dan Tari Perang Nias.

Berdasarkan uraian tersebut penulis tertarik untuk menjadikan sebagai topik penelitian. Maka untuk penulis mengambil judul "Bentuk Penyajian Musik Mamözi Göndra dalam Mengiringi Tari Perang Nias di Sanggar Furai Medan”.

Tujuan penulisan yang ingin dicapai dalam penulisan ini adalah :

1. Untuk mengetahui keberadaan musik Mamözi Göndra dalam mengiringi Tari Perang Nias di Sanggar Furai Medan.

2. Untuk mengetahui instrument Mamözi Göndra dalam mengiringi Tari perang Nias di Nias di Sanggar Furai Medan.

3. Untuk mengetahui fungsi musik Mamözi Göndra dalam mengiringi Tari Perang Nias di Nias di Sanggar Furai Medan.

4. Untuk mengetahui bentuk penyajian musik Mamözi Göndra dalam mengiringi Tari Perang Nias di Sanggar Furai Medan.

\section{Lokasi dan Waktu Penelitian}

Sesuai dengan judul penelitian "Bentuk Penyajian Musik MamÖzi GÖndra dalam mengiringi Tari Perang Nias di Kelurahan Rengas Pulau Kecamatan Medan Marelan ". Maka penelitian dilaksanakan di Sanggar Furai Kelurahan Rengas Pulau Medan. Waktu yang digunakan dalam pelaksanaan penelitian ini dimulai setelah di seminarkan.

\section{Populasi dan Sampel}

\section{Populasi}

Berdasarkan pendapat tersebut maka penelitian ini menggunakan populasi sasaran, sumber tidak didapat dari keseluruhan melainkan sebagian dari lokasi peneltian. Sedangkan yang menjadi populasi adalah Pelatih Musik MamÖzi GÖndra, masyarakat, para penari,dan para pemusik MamÖzi GÖndra dalam mengiringi Tari Perang Nias

\section{Sampel}

Sampelnya adalah Pelatih Musik 1 orang, Pemain GÖndra 2 orang, Pemain Faritia 2 orang, Pemain Aramba 1 orang, Penari Tari Perang Nias 6 orang, Masyarakat 2 orang dan Jumlah Keseluruhan 14 orang.

\section{Teknik Pengumpulan Data}


Teknik pengumpulan data yang dilakukan adalah sebagai berikut:

1. Observasi

2. Wawancara

3. Dokumentasi

4. StudiKepustakaan

\section{Teknik Analisis Data}

Dalam penelitian ini data yang digunakan adalah teknik analisis data kulitatif dimanaproses mencari dan menyusun secara sistematis data-data yang diperoleh dari hasil wawancara, catatan lapangan, dan dokumentasi.

\section{ISI}

\section{A. Keberadaan Sanggar Furai}

Sanggar Furai merupakan sanggar yang digunakan masyarakat Nias untuk latihan dalam musik dan tari, sanggar Furai berpusat di Kelurahan Titi Kuning Kecamatan Medan Johor. Sanggar Furai memiliki 1 cabang yaitu di Kelurahan Rengas Pulau kecamatan Medan Marelan. Sanggar Furai yang terletak di Kelurahan Rengas Pulau dulunya disebut perkumpulan masyarakat Nias (PERMANI), Pendirinya seorang tokoh Seniman dari Nias Selatan yaitu Famaigi Z. Manao yang didirikan pada tahun 1995. Seiring berjalannya waktu, setelah masyarakat Nias merantau di Rengas Pulau maka pengurus lembaga masyarakat Nias bermusyawarah untuk mengalihfungsikan lembaga masyarakat Nias bukan lagi sebagai tempat perkumpulan masyarakat Nias melainkan tempat untuk mempelajari seni budaya Nias seperti musik dan tarian tradisional Nias. Mulai saat itu perkumpulan masyarakat Nias berganti nama Sanggar Furai yang terletak di Kelurahan Rengas Pulo dan berpusat di Kecamatan Medan Johor Kelurahan Titi Kuning. Sanggar Furai yang berada di Kelurahan Rengas Pulau memiliki prestasi yang baik (musik dan tari), sanggar Furai pernah mendapatkan peringkat pertama pertunjukan musik tradisional Nias di Gunung Sitoli pada tahun 2005, dan membawakan pembukaan ulang tahun Kotamadya Gunung Sitoli pada tahun 2009. Anggota yang dimiliki Sanggar Furai di Kelurahan Rengas Pulo mencapai 8 orang.

\section{Instrumen Dalam Musik Mamözi}

\section{Göndra}

\section{Göndra}

Göndra merupakan salah satu alat musik tradisional Nias yang termasuk dalam golongan membranofon, dua sisi, yang berbentuk barel. Kedua sisi Göndra yang dilapisi oleh membran 
mempunyai diameter $57 \mathrm{~cm}$, dimana dibagian bawah membran dilapisi oleh karet sebagai penahan suara biar agar terlalu gaung. Göndra memiliki panjang $70 \mathrm{~cm}$ dan lebar Göndra 60 cm6. Bentuk Göndra menyerupai bentuk Bedug yang ada di mesjid, hanya perbedaannya terletak pada pemukulnya dan ukurannya.

Posisi Göndra digantungkan setinggi $150-180 \mathrm{~cm}$, agar orang yang memainkan Göndra tersebut merasa nyaman dan tidak terganggu. Pada umumnya Göndra digantungkan pada sebuah tiang yang disebut Sanaha Göndra. Panjang tiang tersebut biasanya sekitar $200 \mathrm{~cm}$, dengan lebar sekitar 120cm7. Pada sanaha Göndra tersebut diukir ornamen-ornamen khas budaya Nias yang bewarna merah dan kuning. Bagi masyarakat Nias warna merah melambangkan kekuasaan dan warna kuning melambangkan kemakmuran.

\section{Faritia}

Alat musik ini dahulu adalah barang yang diimpor dari luar pulau Nias, yang semula hanya sebagai bahan barteran dalam sistem perdagangan. Ini membuktikan bahwa alat musik ini bukanlah alat musik yang asli buatan masyarakat Nias, namun dijadikan sebagai alat musik tradisional Nias. Menurut, Faritia ini adalah barang yang diimport dari Jawa sampai saat ini. Pada zaman dulu, jika ada yang ingin memiliki faritia, maka ono Niha akan memesannya kepada pedagangpedagang dari luar pulau Nias sebelum mereka mengadakan transaksi (barter).

\section{Aramba}

Keberadaan alat musik Aramba diyakini sama seperti keberadaan Faritia. Hal ini disebabkan kedua alat musik tersebut sama-sama terbuat dari bahan logam. zaman dahulu di pulau Nias tidak terdapat orang yang melakukan pembuatan berbahan logam, sehingga alat musik ini harus diimpor dari luar pulau Nias.

Cara memainkannya mudah, hanya cukup menghitung dua atau empat ketuk (tergantung kesepakatan pemainnya) dan memukulnya setiap ketukan pertama. Aramba yang dipakai bisa hanya satu, dan bisa juga dua ataupun tiga. Dalam masyarakat Nias, semakin banyak kita menggunakan Aramba, semakin tinggi derajatnya. Hal ini disebabkan karena Aramba adalah salah satu benda yang tergolong mahal dan spesial bagi ono Niha pada zaman dahulu. 
Fungsi Mamözi Göndra Dalam Mengiringi Tari Perang Nias

Dalam konteks tari perang Nias, mamözi göndra mempunyai fungsi. peneliti harus melihat fungsi musik mamözi göndra dalam mengiringi tari perang Nias, penulis akan mendeskripsikan Tari perang nias secara umum.

Tari perang Nias biasanya dilakukan pada acara adat Nias yang bertujuan untuk menyambut dan menyapa para undangan, terutama tamutamu terhormat yang datang pada acara tersebut. Tari perang nias ini biasanya dibawakan oleh sekelompok penari lakilaki, dimana masing-masing penari memakai kostum warna kuning hitam, ataupun merah hitam sesuai dengan kesepakatan pihak penari dengan yang membawa acara. Pada konteks pertunjukan musik tari perang Nias harus memperhatikan langkah-langkah penari pada musik mamözi göndra

\section{Bentuk Penyajian Musik Mamözi} Göndra

Sesuai dengan teori bahwa penyajian sebuah karya seni adalah visualisasi karya secara keseluruhan dimulai dari bentuk atau simbol yang dihadirkan seniman sebagai ungkapan jiwa maupun cara seniman mengemas karya tersebut sehingga karya tersebiut tersaji dihadapan pengamat, selain itu penyajian juga memiliki Unsur-unsur yang meliputi tempat pertunjukan, musik, alat musik, pemain musik, penonton, dan kostum yang disuguhkan kepada yang menyaksikannya, penonton, para pengamat, pembaca, pendengar, khayal ramai pada umumnya.

Adapun bentuk penyajiannya musik mamözi göndra dalam mengiringi tari perang Nias di Sanggar Furai Kelurahan Rengas Pulo adalah sebagai berikut :

1. Persiapan sebelum musik mamözi göndra dimainkan

Sebelum musik mamözi göndra dipertunjukkan, persiapan yang harus dilakukan agar musik mamözi göndra bisa terlaksana dengan baik, harus diawali dengan fohugo (pembuka) yang artinya musik mamözi göndra telah siap untuk dimainkan. Fohugo ( pembuka) memiliki peran dalam Adat Nias seperti dalam musik mamözi göndra, karena jika tidak ada fohugo musik mamözi göndra tidak bisa dimainkan atau dipertunjukkan dalam setiap acara atau Adat Suku Nias.

2. Proses Musik Mamözi Göndra 
Mamözi göndra adalah suatu seperangkat alat musik yang terdiri dari göndra, faritia dan aramba. Gondra adalah salah satu alat musik dari mamözi göndra, Orang yang memainkan Göndra disebut Samözi Göndra. Samözi Göndra terdiri dari dua orang, yaitu Sanaha 1 dan Sanaha 2. Sanaha adalah orang yang memainkan Göndra dengan cara membuat ritme yang konstan dan berulang-ulang. Fungsi Sanaha 1 adalah untuk menjaga tempo dan pulsa bagi Sanaha 2 agar tidak berantakan. Sanaha 2 adalah orang yang memainkan alat musik Göndra dengan cara berimprovisasi sambil menjadikan Sanaha 1 sebagai pedoman dalam segi tempo dan pulsa.

Pada umumnya variasi yang dibentuk oleh Sanaha 2 tidaklah begitu sulit. Sanaha 2 hanya menggunakan ritme-ritme sederhana, seperti ketukan 1/2 dan 1/4. Dalam permainan Göndra, Samözi Göndra tidak mengetahui rudiment8 (single stroke, double stroke, paradidle) dan teknik tersebut tidak pernah diaplikasikan kedalam permainan Göndra.

Faritia adalah alat musik yang menyerupai seperti Gong yang berukuran kecil Satu set faritia dimainkan oleh dua orang, dimana masing-masing memegang satu faritia. Cara memainkannya sangatlah sederhana, yaitu satu orang memukul faritia seperti membuat ketukan/ pulsa, dan satu lagi menyahutnya.

Aramba adalah salah satu alat musik yang menyerupai Gong yang berukuran besar. Instrument aramba ini dipakai sebagai pedoman untuk mengetahui awal ketukan. Cara memainkannya mudah, hanya cukup menghitung dua atau empat ketuk (tergantung kesepakatan pemainnya) dan memukulnya setiap ketukan pertama. Aramba yang dipakai bisa hanya satu, dan bisa juga dua ataupun tiga.

ketiga alat musik ini dimainkan secara bersama-sama setelah salah seorang pemusik mengatakan fohugo (pembuka), setelah fohugo digunakan, musik mamözi göndra telah siap dipertunjukkan dan dimainkan secara bersama-sama.

3. Proses Penutup Musik Mamözi Göndra

Mamözi göndra akan ditutup setelah salah satu pemain musik memberikan kode kepada pemain musik lainnya, musik mamözi göndra harus berhenti secara bersama-sama. Hal ini 
disebabkan karena rasa kebersamaan masyarakat Nias yang erat, Sehingga menjadi suatu kebanggaan tersendiri bagi masyarakat Nias.

Dengan memperhatikan musik mamözi göndra tersebut, unsur-unsur yang membantu musik mamözi göndra itu dalam mencapai perwujudannya yaitu : Seniman, Alat Musik, Kostum dan Tempat Pertunjukkan.

Seniman dalam musik mamözi göndra, untuk melatih dan memainkan musik mamözi göndra pada saat akan ada acara yang telah di inginkan masyarakat Nias untuk memainkan musik mamözi göndra. Seniman musik mamözi göndra dapat juga memberikan kode kepada pemain musik mamözi göndra saat pembukaan musik mamözi göndra maupun penutup musik mamözi göndra.

Alat musik mamözi göndra berperan penting dalam pelbagai acara adat suku Nias seperti acara pernikahan, acara pesta kematian maupun acara pertunjukkan tarian adat, jika alat musik mamözi göndra tidak ada maka pertunjukkan tidak dapat dilangsungkan disebabkan musik mamözi göndra adalah inti dalam setiap pertunjukkan.
Kostum dalam memainkan musik mamözi göndra menyerupai dengan kostum tari perang nias yang berwarna hitam, merah dan kuning. Kostum musik mamözi göndra dapat dilihat pada saat acara dalam adat suku Nias. dan dapat dilihat juga pada saat tari perang Nias dipertunjukkan, karena kostum musik mamözi göndra berhubungan dengan kostum tari perang Nias.

Tempat pertunjukkan musik mamözi göndra dilaksanakan di lokasi yang terbuka dan tidak ada batas tempat memainkan musik mamözi göndra, hanya tempat memainkan musik mamözi göndra tersebut harus memiliki tempat yang luas.

\section{PENUTUP}

\section{Kesimpulan}

Dari uraian-uraian tentang permasalahan dan pembahasan yang telah dikemukaka pada bab-bab sebelumnya, maka pada bab ini penulis mencoba membuat kesimpulan mengenai bentuk penyajian Musik Mamözi GÖndra dalam Mengiring tari Perang Nias di Sanggar Furai Medan.

1. Masyarakat Nias masih tetap menjaga dan menjalankan musik mamözi göndra yang diwariskan 
oleh leluhur mereka hingga saat ini. Musik mamözi göndra dapat ditemukan di setiap sanggar Nias, dan dapat dilihat juga pada setiap kegiatan-kegiatan adat suku Nias.

2. Dalam penyajian musik mamözi göndra, terlebih dahulu kata fahugo (pembuka) dilakukan. Setelah fahugo dilakukan selanjutnya musik mamözi göndra dapat dimainkan secara bersama-sama dengan instrument musik lainnya seperti göndra, faritia dan aramba. Unsur-unsur yang harus terpenuhi dalam penyajian musik mamözi göndra adalah seniman, alat musik, kostum dan tempat pertunjukkan

3. Fungsi musik mamözi göndra yang terdapat dalam penyajian tari perang Nias memiliki 5 fungsi yaitu sebagai berikut:
a. Hiburan
b. Ekspresi Diri
c. Komunikasi
d. Pengiring Tarian
e. Ekonomi

4. Instrumen yang digunakan dalam bentuk penyajian musik mamözi göndra yaitu göndra, aramba, dan faritia. Dalam mamözi göndra terdapat instrumen musik yang memiliki makna pilosofi yaitu instrument aramba dimana semakin banyak instrumen tersebut digunakan dalam penyajian musik mamözi göndra maka semakin tinggi derajat orang yang menyajikan mamözi göndra dalam upacara adat.

\section{DAFTAR PUSTAKA}

Aminudin. 2009."Apresiasi Karya Seni Musik Daerah Nusantara”. Bandung: Sarana Ilmu.

Bungin, Burhan. 2011."Penelitian Kualitatif”. Jakarta: Kencana.

Corazon,CD. 2007. Aminudin. 2009."Apresiasi Karya Seni Musik Daerah Nusantara”. Bandung: Sarana Ilmu.

Traditional Musical Instrument of The Philippines Nevada : FMA digest.

Daminto.2004. "Kerangka teoritis Penelitian”, Jakarta: Gramedia Pustaka 
Djelantik, A.A.M. 2000. ESTETIKA

Masyarakat seni Pertunjukkan Indonesia

Gunawan imam. 2014. " Metode Penelitian Kualitatif: Teorid dan Praktik”.Jakarta: Bumi Akasra.

Harefa, Brian Laso Saro, 2012 dangan judul skripsi "Analisis Fungsional Dan Musikal Ensambel MamÖzi Aramba Dalam Kebudayaan Nias diGunung Sitoli”. Universitas Sumatera utara.

Hidayat,Robby M.Sn.2005.Wawasan Seni Tari. Fakultas Sastra Universitas Negeri Malang.

Kurnia,akbar.2002 dengan judul skripsi "Musik Iringan Tari Mendulang Emas Pada Masyarakat Mandailing Angkola Di SanggarDos Niroha ( Kajian Terhadap Bentuk, Fungsi Dan Makna) Universitas Negri Medan.
Marpaung, Nurlena, 2014. Keberadaan Musik Pengiring Pencak Silat Pada Sanggar Bertuahdi Hamparan Perak Kabupaten Deli Serdang. Universitas Negeri Medan.

Merriam, Alan P. 1964. The Anthopology of Music. Evanston Illinois: North Western University Press.

Miller, Michael. 2002. "The Complete Idiot's Guide to Music Theorg" Indianapolis : Pearson Education,Inc.

Setyadin. 2005. "Metode Penelitian Kualitatif: Teori dan Praktik”. Jakarta: Bumi Akasra.

Silitonga, Dameria Hotma. 2014.

“Teori Musik". Medan: Unimed Press.

Sinaga Delvi, 2015 dengan judul skripsi "Gondang Hasapi Pada Upacara Ritual Parmalim Si Pahasada di Huta Tinggi Kecamatan Laguboti Kabupaten Toba Samosir 
(Kajian Bentuk Penyajian dan Fungsi) ”. Universitas Negeri Medan.

Sinaga Kristian, 2015 dengan judul skripsi “ Bentuk Penyajian Dan Fungsi Musik Pada Upacara Thau Chit Kepercayaan Khonghucu di Yayasan Budi Mulia Kecamatan Lubuk Pakam Kabupaten Deli Serdang ". Universitas Negeri Medan.

Sugiyono. 2010."Metode Penelitian Kuantitatif Kualitatif dan $R \& D ”$. Bandung: Alfabetha.

Sujarweni Wiratna. V. 2014."metodologi Penelitian lengkap, praktis, dan mudah dipahami”. Yogyakarta: pustaka baru press.

Sukardi, 2003. Metode Penelitian. Bandung: Alfabeta.

Supranto.2004 .Prosedur Penelitian, Jakarta: Penerbit PT. Rineka Cipta.

Susetyo, Bagus. 2009. "Handout Materi Pembelajaran: Kajian Seni
Pertunjukan”. Semarang. Unnes press.

\section{http://www.etnomusikologiusu.com}

